\title{
Asignaturas de educación física en los planes de estudios de la Escuela española (1857-1970)
}

\author{
Physical education subjects in Spanish school curricular \\ regulations (1857-1970)
}

\author{
Antonio D. Galera Pérez \\ Universidad Autónoma de Barcelona
}

Recibido: 05/04/2018

Aceptado: 23/11/2018

\begin{abstract}
Based on an exhaustive search through two of the main Spanish legal databases, specially GAZETA or the updated legislation, by the 'Boletín Oficial del Estado', and Westlaw, formerly Aranzadi, this paper summarises the curricular legal regulations undertaken in Spain between 1857 and 1970, a period of full applicability for the so-called Moyano Law, regarding the physical education contents in two curricular levels: elementary education and middle education. We have found out a profuse legislation for the secondary education in the whole period, as to a relevant attention payed to physical education during the former Francoist phase. The interest of this article lies in the application of three innovative methodological aspects to a classic work of source compilation. First of all, the method of analysis and systematization of the norms immediately objectifies the different performance of the Administration of each period in both levels. Secondly, it is undertaken for the first time the accurate listing of the different Baccalaureate curricula as legislated by the Francoism, never synthetically systematized until now. Finally, taking advantage of the current preferential use of the telematic edition, the related series of rules are highlighted in each table, which facilitates the visualization of training itineraries, for further specialized specialized studies.
\end{abstract}

KEY WORDS: Educational legislation; Curriculum framework; Elementary education; Secondary education; Physical education

\section{RESUMEN}

Partiendo de una cuidadosa búsqueda en las principales bases de datos legislativos españolas, especialmente GAZETA o la legislación consolidada, del Boletín Oficial del Estado, y Westlaw, antigua Aranzadi, se sintetiza en este trabajo la evolución normativa de los planes de estudio españoles promulgados entre 1857 y 1970, el período de plena vigencia de la Ley Moyano, relativos a la presencia de la educación física en dos niveles de la educación básica: educación primaria y educación secundaria. Encontramos una profusa legislación de la enseñanza secundaria en todo el período, y una atención relevante prestada a la educación física durante la etapa altofranquista. El interés del artículo reside en la aplicación de tres aspectos metodológicos innovadores a un clásico trabajo de recopilación de fuentes. En primer lugar, el método de análisis y sistematización de las normas objetiva de forma inmediata la diferente actuación de la Administración de cada período en los dos niveles analizados. En segundo lugar, se acomete por primera vez el repertorio detallado de los diversos planes de estudios del Bachillerato regulados por el franquismo, nunca hasta ahora sistematizados sintéticamente. Por último, aprovechando el actual uso preferente de la edición telemática, se resalta en cada tabla las series de normas relacionadas, lo que facilita la visualización de itinerarios de formación, de cara a ulteriores estudios monográficos especializados.

PALABRAS CLAVE: Legislación educativa; Planes de estudios; Enseñanza primaria; Enseñanza secundaria; Educación física

\footnotetext{
Dirección de correspondencia:

Antonio D. Galera Pérez. Departamento Didáctica de la Expresión musical, plástica y corporal, Universidad Autónoma de Barcelona (España). E-mail: antonio.galera@uab.es. ORCID: https://orcid.org/ 0000-00026272-6494
} 


\section{Advertencia preliminar}

En aplicación de la doctrina clásica de Zeigler,1 en el texto de este artículo diferenciaremos entre, por un lado, educación física, en minúsculas, para designar un ámbito de intervención educativa, equiparable a los de educación intelectual, moral, etc., o una materia de estudio doctrinal que puede impregnar una o varias asignaturas, y por otro, Educación Física con mayúsculas, en tanto que denominación de una asignatura concreta en ciertos períodos, que contendría aspectos de educación física, no necesariamente exclusivos.

\section{Claves utilizadas}

Para evitar reiteración en las numerosas tablas formadas por el autor en este estudio, siguen a continuación las claves de los organismos, publicaciones y normas que aparecen citadas.

Organismos legisladores:

DCUL $=$ Departamento de Cultura de la Generalidad de Cataluña

JDN= Junta de Defensa Nacional

$\mathrm{JE}=$ Jefatura del Estado

MCIOP $=$ Ministerio de Comercio, Industria y Obras públicas

MEN $=$ Ministerio de Educación Nacional

MFOM= Ministerio de Fomento

MGyJ = Ministerio de Gracia y Justicia

MIPBA = Ministerio de Instrucción pública y Bellas Artes

MIPS= Ministerio de Instrucción pública y Sanidad

$\mathrm{RG}=$ Regencia del Gobierno

$\mathrm{SNPE}=$ Servicio nacional de Primera enseñanza

Claves de publicaciones:

BOE $=$ Boletín Oficial del Estado

BOJDN = Boletín Oficial de la Junta de Defensa Nacional

BOMIP = Boletín Oficial del Ministerio de Instrucción pública y Bellas Artes

DOGC $=$ Diari Oficial de la Generalitat de Catalunya

GM= Gaceta de Madrid

$\mathrm{GR}=$ Gaceta de la República

Normas:

$$
\begin{array}{l|l}
\mathrm{C}=\text { Circular } & \mathrm{O}=\text { Orden } \\
\mathrm{D}=\text { Decreto } & \mathrm{OC}=\text { Orden circular } \\
\mathrm{DL}=\text { Decreto-ley } & \mathrm{RD}=\text { Real decreto } \\
\mathrm{L}=\text { Ley } & \mathrm{RO}=\text { Real orden }
\end{array}
$$

\section{Introducción}

La Ley Moyano, de 1857, representa la culminación del esfuerzo de modernización del sistema educativo español, encetada a raíz del fallecimiento del rey Fernando VII (1833) y la concomitante necesidad de alianza de la Monarquía con el liberalismo, a causa de la rebelión que ésta hubo de afrontar por la cuestión sucesoria y que dio pie a las guerras carlistas. Esta Ley, con algunos parches más o menos duraderos, estaría plenamente vigente hasta la Ley General de Educación, de 1970.

En este trabajo nos planteamos sintetizar el esfuerzo legislativo desarrollado en los planes de estudios de dos pilares del sistema: la enseñanza primaria, en cuanto educación común para todos los

1 Zeigler, E. F. (1977). Relationships in Physical Education: a viewpoint from history and philosophy. 'Relationships in Physical Education', The Academy Papers, 11, septiembre 1977, Washington, D. C., The American Academy of Physical Education. 
niños y niñas, y el de la enseñanza secundaria, su vía actual de continuidad en coherencia con el proceso tradicionalmente preconizado por la Escuela Unificada. Esta síntesis será realizada a través de la creación de tablas cronológicas detalladas, de manera que se facilita notablemente el acceso a cada fuente evitando el riesgo de crear una profusa red de enlaces telemáticos que podrían quedar mayoritariamente obsoletos con cualquier modificación de los accesos.

Partiendo de una exhaustiva búsqueda en las principales bases de datos, especialmente GAZETA y la legislación consolidada, del Boletín Oficial del Estado, y Westlaw-Aranzadi, complementada a veces con búsquedas físicas en Boletines del Ministerio, estudiaremos sintéticamente las características generales de las sucesivas reformas del período, que a efectos metodológicos agruparemos en tres etapas histórico-educativas: el liberalismo a partir de la Ley Moyano (1857-1931), la II República (1931-1939) y el franquismo hasta la Ley General de Educación, etapa que denominaremos altofranquismo (1936-1970), por marcar esta Ley un antes y un después en el sistema educativo del franquismo.

En efecto, hasta 1970, el sistema estuvo arrastrando las consecuencias de un doble proceso normativo. Por un lado, la progresiva ampliación del límite superior de la edad de terminación de la Enseñanza primaria, que de los 9 años establecidos por la Ley Moyano fue elevándose hasta los 12 años $(1901,1911)$, los 13 (1913) y los 14 (1923, 1937); el franquismo estableció incluso una etapa, no obligatoria, hasta los 15 (1945).

Por otro lado, como la Enseñanza secundaria, llamada Bachillerato durante todo el período objeto de este análisis, mantuvo su edad de inicio, el llamado 'ingreso', a los 10 años, las edades comprendidas entre 10 y 12, 13 ó 14-15 conformaban en la Enseñanza primaria una 'vía muerta' sin continuidad pedagógica normativa: estaba nutrida por niños y, en mucha menor medida, niñas, sin futuro académico, para los que sus familias consideraban más útil el mundo laboral (Galera Pérez, 2015a).

En el estudio dedicaremos atención a los aspectos de educación física, en tanto que representativos de la evolución de la doctrina pedagógica hacia concepciones integrales de la educación, que sólo en parte han encontrado hasta ahora su acomodo normativo.

\section{La Enseñanza primaria}

\subsection{Aspectos generales}

La nota común a todo el período estudiado, con la excepción de la II República, es la falta de interés práctico de los sucesivos gobiernos y regímenes en la regulación normativa de contenidos de este nivel educativo.

En la tabla 1 que sigue, resumen de las reformas de la Enseñanza primaria desde 1812, hemos prescindido de las promulgadas para las Escuelas de párvulos porque sus planes de estudios, aunque se regularon de forma muy interesante para la educación física, tuvieron un ámbito teórico y práctico de implantación muy restringido. 
Tabla 1

Planes de estudios de la Enseñanza Primaria (1812-1970)

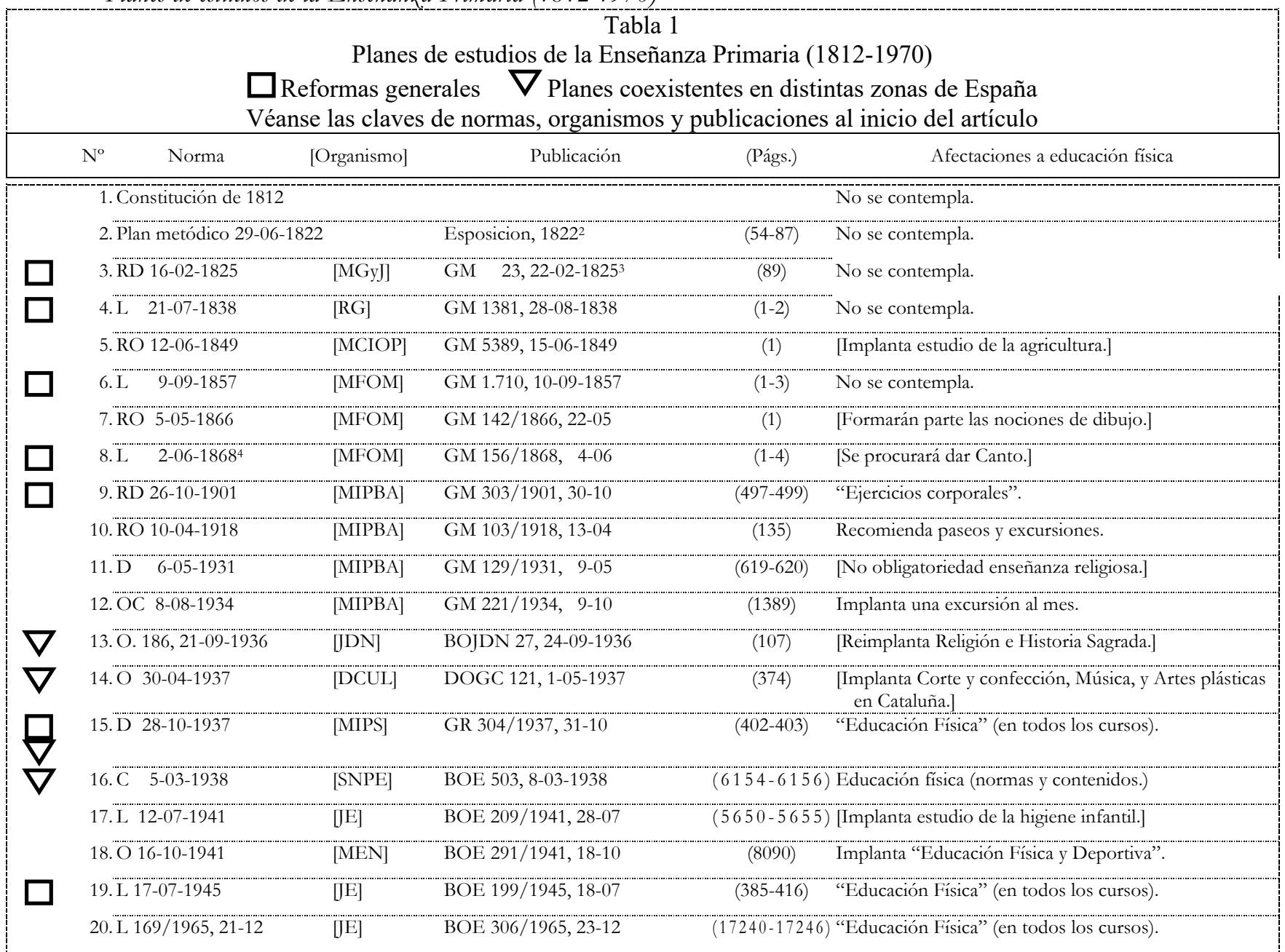

Como vemos, entre 1857 y 1970 sólo podemos encontrar reformas generales de la Educación primaria, aparte de la inicial de 1857, en 1868, 1901, 1937 y 1945; puesto que la reforma de 1868 se derogó a los pocos meses, sin llegar a implantarse prácticamente, y el plan de la II República se promulgó cuando ya estaba fuera del control del gobierno la mayoría del territorio nacional, se puede decir que hasta 1970 sólo hubo tres planes de estudios oficiales de Educación primaria en España: el de la Ley Moyano de 1857, el de 1901, y el de 1945, que sufrió algunas adaptaciones en 1965. Todas las demás fueron reformas parciales que salían al paso de deficiencias sobrevenidas, o adaptaciones coyunturales de aspectos que habían quedado demasiado obsoletos.

Desde un punto de vista pedagógico, la reforma más avanzada del período estudiado, con diferencia sobre las demás, fue la republicana de 1937, que poco llegaría a aplicarse, pues las prioridades iniciales del gobierno en materia de Enseñanza primaria fueron la construcción de

2 Proyecto de Plan metódico de Primera enseñanza presentado [á 13 de Noviembre de 1821] á la Dirección General de Estudios por la comisión nombrada con este objeto [aprobado por las Cortes en 29 de junio de 1822]. En Esposicion sobre el estado de la enseñanza pública hecha á las Córtes por la Direccion General de Enseñanz̧a, Madrid, Imp. Albán y C $C^{a}, 1822$.

${ }^{3}$ Reglamento publicado en Decretos del Rey Nuestro Señor Don Fernando VII,... 1825, [compilados] por don Josef María de Nieva, tomo décimo. Madrid: Imp. Real, 1826, 51-88.

${ }^{4}$ Derogada por Decreto-Ley de 14 de Octubre de 1868 [MFOM] (GM, 189/1868, de 15 de Octubre, 4-5). 
Escuelas, el concomitante aumento del número de maestros y maestras, su dignificación económica y social, y la modernización de metodologías, más que la propia reforma del plan de estudios, y cuando ésta llegó, en plena Guerra Civil, ya estaba perdida la mayor parte del territorio. Cabe mencionar, también en esta etapa, la labor del C.E.N.U. (Consejo de la Escuela Nueva Unificada) en la Región Autónoma de Cataluña, que creó una red de Escuelas que coexistió con la del Estado, y en la que también fueron prioritarias la creación de centros y la modernización de metodologías, más que la modificación del plan de estudios.

\subsection{Aspectos de educación física}

Con anterioridad a 1931, la reforma de 1901 había introducido oficialmente en la Escuela los "ejercicios corporales", sin previsión de su impartición por cursos o grados ni asignación horaria, lo que era normal en la época; al no existir tampoco un mínimo número de maestros o maestras preparados, la impartición de estos ejercicios dependía del interés y celo profesional de cada uno.

Por otra parte, encontramos recomendaciones normativas para programar paseos y excursiones, que en la época tenían una consideración de actividad física destacada, puesto que la ausencia de medios de transporte masivos y baratos conllevaba la necesidad de efectuar a pie tales prácticas. Ello, no sólo no era considerado una obligación sobrevenida, sino que era norma: las clases populares, cuya institución educativa "natural" desde la óptica del liberalismo decimonónico era la Escuela pública, se desplazaban habitualmente a pie, por lo que, desde el punto de vista físico, la recomendación a los maestros de efectuar paseos y excursiones con los alumnos era simplemente aplicar a la vida escolar la práctica de la vida cotidiana.

Tanto el plan republicano como las reformas parciales del C.E.N.U. tuvieron en gran consideración la educación física o sus paradigmas más habituales (especialmente, movimiento y naturaleza). Así, el plan republicano de 1937 prescribía "Educación Física" en todos los cursos y establecía por primera vez en nuestra historia educativa primaria un horario detallado para cada grupo de materias, con lo que se aseguraba la proporción que del tiempo escolar debía dedicarse a cada una. Este plan y las reformas del C.E.N.U. preveían una dosificación de actividades intelectuales y actividades prácticas, así como la presencia de la experimentación práctica como base del aprendizaje infantil.

Durante el franquismo se prescribió "Educación Física" en todos los cursos, pero sin asignación horaria oficial hasta 1965; aunque es cierto que casi todos los programas y manuales de la asignatura efectuaban previsiones horarias, no es menos cierto que éstas no emanaban del Ministerio de Educación, sino de los organismos políticos encargados de la educación física, que actuaban al margen del sistema educativo o, mejor dicho, a los que el sistema educativo no tenía en cuenta en la práctica: eran las llamadas asignaturas 'marías', entre las que además de "Educación Física" se contaban la "Formación del Espíritu Nacional", la "Religión" y las llamadas "Enseñanzas del Hogar", éstas reservadas a las niñas.

\section{Los Bachilleratos}

Desde 1857, la atención prestada a los estudios secundarios ha superado por lo general la de los otros niveles. Con anterioridad a 1931, las reformas de la Segunda enseñanza giraban siempre alrededor de un único plan de estudios, concebido como preparatorio para el ingreso en la Universidad, al que cada gobierno de turno pretendía infundir su rasgo distintivo, que en no pocas ocasiones quedaba reducido al papel que había de tener la educación física. En efecto, el estudio de las reformas de este nivel educativo muestra la importancia diferencial que la Administración educativa le ha concedido en todas las etapas históricas, con independencia del régimen político que consideremos.

Desde la promulgación de la Ley Moyano de 1857 hasta el final de la I Restauración, los estudios de Bachillerato o "estudios literarios" fueron objeto de tantas reformas como cambios de signo político alternaron en el poder, para acomodar sus características pedagógicas a unas supuestas 
ideologías contrapuestas; muchas de estas reformas fueron únicamente "cosméticas", para dejar constancia del cambio de gobierno, y en no pocas ocasiones se centraron principalmente en la consideración académica de la asignatura de Gimnasia.

En la II República se acomete también una importante labor reformista, iniciada por una reacción contra el último plan de la Restauración, el plan Callejo; coexistieron varios planes de Bachillerato, de alcance limitado y duración transitoria, aspectos ambos forzados por las circunstancias políticas.

El franquismo, además de legislar en contra de lo proyectado por la II República, desarrolla una febril actividad reformista, que iguala en pocos años la de todo el período anterior a la República, pero con una finalidad muy loable, desde un punto de vista estrictamente educativo: incrementar su implantación entre las clases populares.

\subsection{Los "estudios literarios" hasta 1931}

\subsubsection{Aspectos generales}

La Ley Moyano no preveía una continuidad entre los estudios primarios y los secundarios: a pesar de que los niños y en menor medida niñas acababan su escolaridad obligatoria a los 9 años de edad, los requisitos de acceso a los estudios de Bachillerato eran tan elevados en comparación con el nivel de los escolares, que sólo continuaban estudiando los que "servían para estudiar"; se producía de hecho un vacío que, como hemos comentado, se fue agravando con el tiempo, a medida que el aumento de años de la obligatoriedad de escolarización fue retrasando la edad de finalización de la Primera enseñanza, al tiempo que permanecía invariable la edad de inicio del Bachillerato.

Este progresivo vacío en la continuidad de estudios de la Primera a la Segunda enseñanza hizo evidente a los claustros de los Institutos la necesidad de formar directamente a sus futuros alumnos para que pudieran superar el examen de ingreso: la Administración educativa se ve así obligada a autorizar la apertura de los llamados "Colegios internos", establecidos en los propios Institutos o en su cercanía, con la misión de preparar a los escolares que "sirvieran para estudiar". ${ }^{5}$ Esta necesidad de "cantera" se hizo más acuciante a medida que aumentaba la aludida separación real entre la Primera y la Segunda enseñanza.

Tabla 2

Planes de estudios del Bacbillerato durante el liberalismo (1857-1931)

\begin{tabular}{|c|c|c|c|c|}
\hline $\begin{array}{r}\mathrm{Pl} \\
\text { Véans }\end{array}$ & $\begin{array}{l}\text { lanes de estud } \\
\text { se las claves c }\end{array}$ & $\begin{array}{r}\text { Tabla } 2 \\
\text { ios del Bachillerato dur } \\
\text { e normas, organismos y }\end{array}$ & $\begin{array}{l}\text { nte el liber } \\
\text { publicacior }\end{array}$ & $\begin{array}{l}\text { alismo (1857-1931) } \\
\text { nes al inicio del artículo }\end{array}$ \\
\hline Norma & [Organismo] & Publicación & (Págs.) & Afectaciones a educación física \\
\hline 1.L $\quad 9-09-1857$ & [MFOM] & $\begin{array}{l}\text { GM 1.710, } 10-09- \\
1857\end{array}$ & $(1-3)$ & No contempla. \\
\hline 2. $\mathrm{RD} 23-09-1857$ & [MFOM] & $\begin{array}{l}\text { GM 1.724, 24-09- } \\
1857\end{array}$ & $(1-3)$ & No contempla. \\
\hline 3. RD 26-08-1858 & {$[\mathrm{MFOM}]$} & GM 243/1858, 31-08 & (1) & No contempla. \\
\hline 4. RD 21-08-1861 & [MFOM] & GM 238/1861, 26-08 & (1) & No contempla. \\
\hline 5. RD 9-10-1866 & [MFOM] & GM 285/1866, 12-10 & (1) & No contempla. \\
\hline 6. DL 25-10-1868 & 8 [MFOM] & GM 300/1868, 26-10 & $(3-7)$ & No contempla. \\
\hline 3-06-1873 & 3 [MFOM] & GM 159/1873, 8-06 & $(660-662)$ & "Gimnástica higiénica". \\
\hline
\end{tabular}

\footnotetext{
${ }^{5}$ Real decreto de 6 de Noviembre de 1861 sobre establecimiento de Colegios en los Institutos de segunda enseñanza [MFOM] (GM, 311/1861, de 7 de Noviembre, 1); derogado por Decreto de 9 Febrero de 1869 [MFOM] (GM, 40/1869, de 9 Febrero, 3).
} 


\begin{tabular}{|c|c|c|c|c|}
\hline \multicolumn{5}{|c|}{$\begin{array}{l}\text { Tabla } 2 \\
\text { Planes de estudios del Bachillerato durante el liberalismo (1857-1931) } \\
\text { Véanse las claves de normas, organismos y publicaciones al inicio del artículo }\end{array}$} \\
\hline Norma & [Organismo] & Publicación & (Págs.) & Afectaciones a educación física \\
\hline 8.D $10-09-1873^{6}$ & [MFOM] & GM 254/1873, 11-09 & (1) & No contempla. \\
\hline 9. RD 13-08-1880 & [MFOM] & GM 229/1880, 16-08 & $(499-502)$ & No contempla. \\
\hline 10. $\mathrm{RO} \quad 1-09-1893^{7}$ & [MFOM] & GM 253/1893, 10-09 & $(969)$ & $\begin{array}{l}\text { "Gimnástica" obligatoria para los } \\
\text { alumnos de primer año, clase } \\
\text { alterna. }\end{array}$ \\
\hline 11. RD 16-09-1894 & [MFOM] & GM 261/1894, 18-09 & $(982-988)$ & $\begin{array}{l}\text { Prácticas gimnasia diaria en los } 4 \\
\text { años. }\end{array}$ \\
\hline 12. RD 12-07-1895 & [MFOM] & GM 194/1895, 13-07 & $(166)$ & "Gimnástica" bisemanal voluntaria. \\
\hline 13. RD 14-10-1896 & [MFOM] & GM 290/1896, 16-10 & $(177)$ & $\begin{array}{l}\text { "Gimnástica", lección diaria en dos } \\
\text { de los cursos a elección de los } \\
\text { alumnos. }\end{array}$ \\
\hline 14. RD 13-09-1898 & [MFOM] & GM 257/1898, 14-09 & $(1133-1138)$ & "Gimnástica" voluntaria 8 \\
\hline 15. RD 26-05-1899 & [MFOM] & GM 150/1899, 30-05 & $(725-727)$ & "Gimnasia" voluntaria.? \\
\hline 16. RD 20-07-1900 & [MIPBA] & GM 203/1900, 22-07 & $(307-310)$ & "Gimnasia" en los seis años. ${ }^{10}$ \\
\hline 17. RD 17-08-1901 & [MIPBA] & GM 231/1901, 19-08 & $(790-795)$ & $\begin{array}{l}\text { "Gimnasia" alterna en los seis } \\
\text { años. }{ }^{11}\end{array}$ \\
\hline 18. RD 6-09-1903 & [MIPBA] & GM 259/1903, 16-09 & $(2391-2392)$ & $\begin{array}{l}\text { "Gimnasia" en } 2 .^{\circ} \text { y } 3 .^{\circ} \text { años, } \\
\text { Fisiología e Higiene en } 5 .^{\circ}\end{array}$ \\
\hline 19. RD 25-08-1926 & [MIPBA] & GM 240/1926, 28-08 & $(1234-1237)$ & $\begin{array}{l}\text { Ejercicios de educación física, paseos } \\
\text { y juegos deportivos todos los } \\
\text { cursos. }^{12}\end{array}$ \\
\hline 20. RD 18-02-1927 & [MIPBA] & BOMIP 16/1927 & & $\begin{array}{l}\text { [Bachillerato Universitario de } \\
\text { Idiomas.] }\end{array}$ \\
\hline
\end{tabular}

Una segunda medida que muestra el mayor interés de la Administración liberal por la Segunda enseñanza fue la atención que prestó a la reforma de sus planes de estudios, con tanto entusiasmo que los planes de Bachillerato duraban lo que los gobiernos. En la tabla 2 anterior se puede comprobar la existencia de hasta 20 planes de estudios diferentes entre 1857 y 1931; para un total aproximado de 72 años y medio, vemos que cada plan duró una media de unos tres años y medio, aunque si descontamos los 23 años que duró el Plan Bugallal de 1903, la duración media de los otros 19 planes disminuye hasta 2,6 años o, lo que es lo mismo, entre 1857 y 1903, cada estudiante de Bachillerato tuvo que cambiar de plan de estudios por término medio un mínimo de dos veces, con

\footnotetext{
${ }^{6}$ Suspende la ejecución del Decreto anterior, por lo que se vuelve a la organización del Decreto-ley de 25 de Octubre de 1868, que no contemplaba la educación física.

7 Por Real decreto de 26 de Julio de 1893 se habían creado diez clases de Gimnástica en los Institutos de cabeceras universitarias; esta Real orden las extiende a todos los demás y establece horarios.

${ }^{8}$ «Art. 3. ${ }^{\circ}$ Todas las asignaturas comprendidas en el cuadro anterior son de estudio obligatorio, salvo lo prescrito en los Reales decretos de... 12 de Julio de 1895...» (GM, 194/1895, de 13 Julio, 166); cuyo Art. 2. ${ }^{\circ}$ declaraba voluntaria la Gimnástica.

9 Junto con "Dibujo", constituían el grupo de Educación física y artística.

10 Reducida su frecuencia a cuatro cursos por Real orden de 31 de Agosto de 1900 distribuyendo las materias de estudios de los seis años del Bachillerato [MIPBA] (GM, 247/1900, de 4 Septiembre, 926).

${ }^{11}$ Se cambia el nombre de la asignatura por el de Juegos y ejercicios corporales y se eleva su frecuencia a diaria por Real decreto de 29 de Septiembre de 1901 aprobando el reglamento para el régimen y gobierno de los Institutos generales y técnicos [MIPBA] (GM, 275/1901, de 2 Octubre, 33-36).

${ }^{12}$ Se fija su frecuencia en 1 hora diaria por Real orden de 3 de Septiembre de 1926 disponiendo que el número de horas de Cátedra correspondiente a cada asignatura, sea semanalmente el que se indica [MIPBA] (GM, 248/1926, de 5 Septiembre, 1.468-1.469).
} 
el coste añadido de trámites administrativos, adaptaciones de planes de estudios generales o para casos concretos, convalidaciones, asignaturas nuevas no previstas en el plan anterior, etc.

\subsubsection{Aspectos de educación física}

Con anterioridad a 1931, y salvo un efímero plan de 1847 y uno no aplicado de 1873, éste durante la I República, los planes de estudios de Bachillerato del liberalismo no comenzarían a prescribir materias de educación física de forma regular y extensiva hasta 1893, aunque con una base doctrinal poco coherente: unos planes la contemplan en todos los cursos $(1894,1900,1901,1926)$, otros, sólo en dos (1896, 1903); alguno la prescribe diariamente (1894), otros, un par de días a la semana (1895); en unos planes es obligatoria $(1893,1894,1896,1900,1901,1926)$, otros la hacen voluntaria $(1895,1898,1899)$; en unos planes hay exámenes, en otros, simple certificado de aprovechamiento... En bastantes casos, la principal diferencia entre un plan de Bachillerato y el siguiente estribaba únicamente en el tratamiento académico o pedagógico que se daba a la educación física.

3.2. Los planes coyunturales de la República

\subsubsection{Aspectos generales}

Por causas diferentes, la II República mantuvo la misma política que la Restauración, efectuando varias reformas de la Segunda enseñanza y autorizando también la creación de "Escuelas preparatorias", en $1931^{13}$ y 1935, ${ }^{14}$ si bien es verdad que las suprimió en 1937, cuando por fin pudo comenzar a reformar la Primera enseñanza en su camino hacia la Escuela Única. En la tabla 3 siguiente se puede apreciar la regulación de hasta cuatro sucesivos planes republicanos de Bachillerato, formados cada uno de ellos por reformas parciales acumulativas, quizás por falta de tiempo y de sosiego para aplicarse a una reforma global, que por otra parte no era prioritaria en la política republicana:

- Tras una drástica suspensión del plan de la Dictadura de 1926 (plan Callejo), que había suscitado un amplio rechazo social, se optó por volver al plan anterior, de 1903, con algunas adaptaciones (el plan de adaptación) que fueron promulgándose anualmente curso por curso.

- Mientras se estaba desarrollando esta adaptación, se diseñó un plan de transición, también desarrollado curso por curso.

- El plan propiamente republicano llegaría en 1934, durante el bienio negro (plan Villalobos).

- Ya en plena Guerra Civil (1936), se creó un plan abreviado para jóvenes obreros, que se desarrollaba en dos cursos, divididos en sendos semestres, en horarios vespertinos.

Cabe resaltar que los cuatro planes funcionaron simultáneamente, lo cual complicaría notablemente la vida académica y administrativa de los Institutos.

Aspectos de educación física

El plan de adaptación, al volver al plan anterior, de 1903, contemplaba por tanto "Gimnasia" en $2 .^{\circ}$ y 3 r. cursos y "Fisiología e Higiene" en 5. ${ }^{\circ}$; mientras se estaba desarrollando esta adaptación, se diseñó el plan de transición, que contemplaba "Educación Física" como asignatura en $10^{\circ}$ y $2 .^{\circ}$ cursos. El plan Villalobos por su parte, contemplaba "Juegos y deportes" sin consideración de

\footnotetext{
${ }^{13}$ Decreto de 25 de septiembre de 1931 declarando que, en donde las condiciones materiales lo permitan y las exigencias pedagógicas lo aconsejen, podrán los Claustros de los Institutos Nacionales de Segunda enseñanza organizar Escuelas preparatorias para el ingreso en dichos Centros [MIPBA] (GM, 269/1931, de 26 Septiembre, 2.021).

${ }^{14}$ Decreto de 7 de Septiembre de 1935 disponiendo que los Claustros de los Institutos de Segunda enseñanza podrán organizar Escuelas preparatorias para el ingreso en los mismos [MIPBA] (GM, 255/1935, de 12 Septiembre, 2.022-2.024).
} 
asignatura, en la tradición de la Institución Libre de Enseñanza, y sin asignación por cursos. El plan abreviado para obreros no contemplaba materias de educación física.

Vemos, por tanto, una tendencia a las oscilaciones normativas en modo similar al que habíamos detectado en el liberalismo.

Tabla 3

Planes de estudio del Bacbillerato durante la II República (1931-1939)

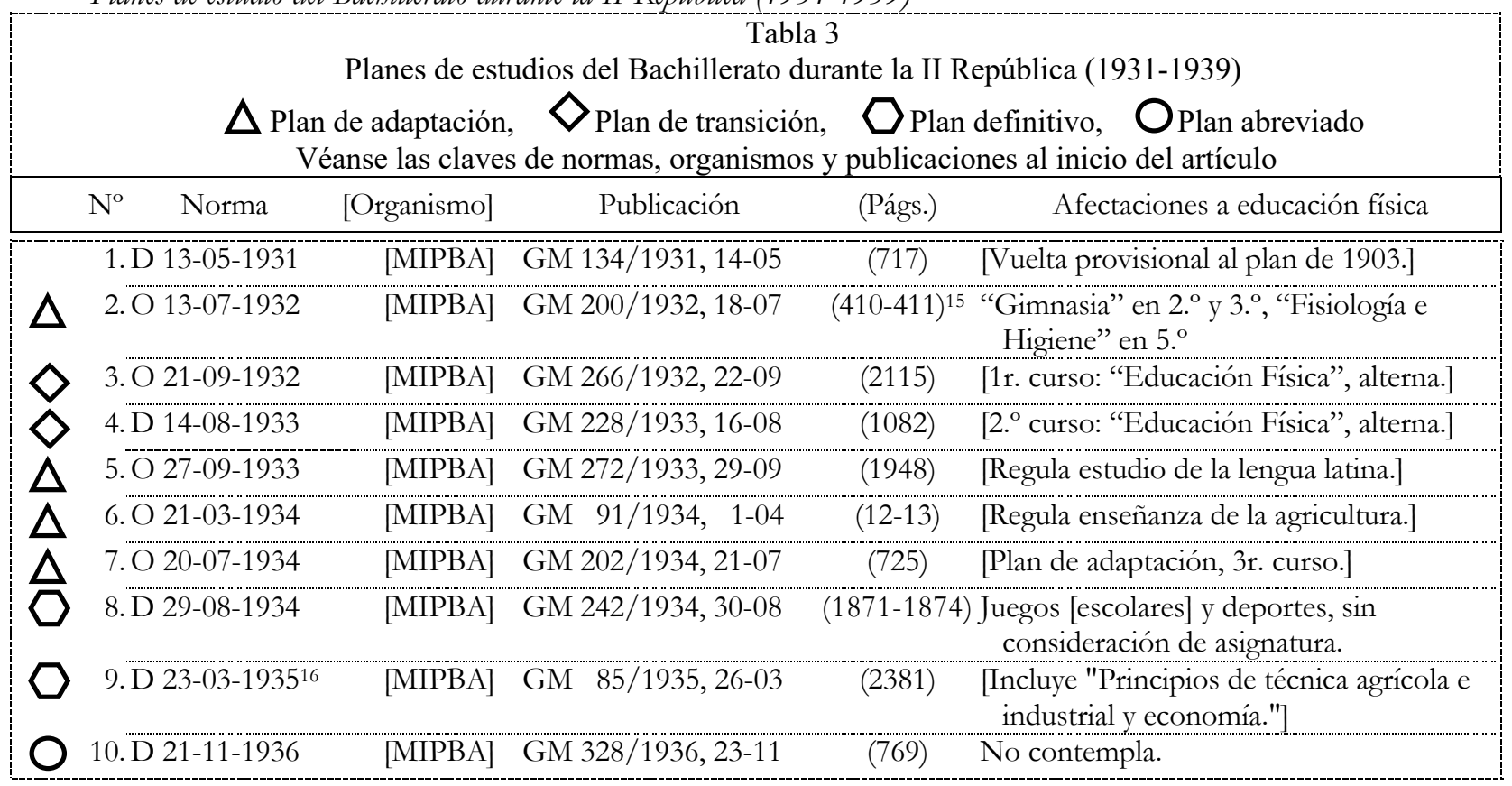

3.3. Bachillerato general, bachillerato para obreros: los planes del altofranquismo

\subsubsection{Aspectos generales}

El franquismo, por supuesto, anuló toda la legislación republicana y, en la tradición anterior a la República, autorizó también la creación de Escuelas preparatorias ${ }^{17}$ al tiempo que dedicó sus primeros esfuerzos administrativos a regular el Bachillerato, ya durante la guerra. En total, se realizaron tres reformas, la inicial de 1938 y dos sucesivas en 1953 y 1957, que evolucionaron en sentido de una progresiva simplificación del demasiado erudito y sobrecargado plan de 1938, y cuya principal novedad fue el establecimiento de dos niveles, Bachillerato Elemental y Bachillerato Superior, con sendos exámenes de Reválida al final de cada uno (tabla 4, siguiente).

En este período se hizo un esfuerzo notable por difundir este nivel de estudios entre amplias capas de la población, creándose estudios más prácticos, el llamado Bachillerato Laboral, también con dos niveles, Elemental y Superior, y con la peculiaridad de que los planes de estudios eran diferentes para chicos y chicas, contemplándose para ellos profesiones "masculinas" y para ellas, "femeninas". Sus respectivos y sucesivos planes de estudios llegaron a alcanzar notoria

\footnotetext{
${ }^{15}$ Corrección de errores, GM, 207/1932, de 25 Julio, 658; es el llamado “plan de adaptación” (del de 1903) que había sido establecido provisionalmente para el curso 1931-1932 por Decreto de 7 de Agosto de 1931 [MIPBA] (GM, 220/1931, de 8 Agosto, 1.058-1.061) y parcialmente para los Institutos locales por Decreto de 8 de Septiembre de 1931 [MIPBA] (GM, 252/1931, de 9 Septiembre, 1.733-1.734).

16 Derogado por el Decreto de 21 de Enero de 1936 [MIPBA] (GM, 23/1936, de 23 Enero, 700-701).

17 Orden de 31 de octubre de 1940 por la que se dictan normas sobre el régimen interno de los Institutos de Enseñanza Media [MEN] (BOE, 311/1940, de 6 noviembre, 7.633-7.635).
} 
heterogeneidad normativa, con frecuentes reformas y sus concomitantes sistemas de convalidaciones, tanto dentro de cada sistema de bachillerato como entre ambos (planes de adaptación de bachilleres universitarios en bachilleres laborales) que debieron de necesitar un elevado aparato administrativo y docente (tabla 5, siguiente).

En conjunto se produjo un sistema de Segunda enseñanza bastante complejo e incluso confuso, que fue resuelto unificando los diversos Bachilleratos Elementales en 1967, quedando a partir de entonces establecido un único Bachillerato Elemental para todos los jóvenes. Quedarían pendientes de unificar los Bachilleratos Superiores, lo que se haría en la Ley General de Educación de 1970.

En las tablas 4 (Bachillerato general) y 5 (Bachillerato laboral) siguientes, se puede comprobar que el número total de reformas de los Bachilleratos franquistas igualó, en menos de 29 años, el de las efectuadas por el liberalismo en 72 años y medio (20 reformas en cada período), si bien es cierto que su alcance y diversidad de itinerarios no son comparables.

Tabla 4

Planes de estudio del Bacbillerato durante el altofranquismo (1936-1970)

\begin{tabular}{|c|c|c|c|}
\hline \multicolumn{4}{|c|}{$\begin{array}{c}\text { Tabla } 4 \\
\text { Planes de estudios del Bachillerato general durante el altofranquismo (1936-1970) }\end{array}$} \\
\hline & $\mathrm{N}^{\circ}$ Norma y fecha & Drganismo] & Afectaciones a educación física \\
\hline & 1.L $20-09-1938$ & {$[\overline{\mathrm{JE}}]$} & $\begin{array}{c}\text { BOE 85/1938, 23-09 (1385-1395) "Educación artística, física y patriótica", } 6 \\
\mathrm{~h} / \text { sem x } 7 \text { cursos. }\end{array}$ \\
\hline$\square$ & 2. $\mathrm{L}$ 26-02-1953 & [JE] & $\begin{array}{c}\text { BOE 58/1953, 27-02 (1119-1130) Alusiones en Preámbulo y Arts. 10, 13, 34, 45, } \\
63,85 .\end{array}$ \\
\hline$\square$ & 3. D 12-06-1953 & {$[\mathrm{MEN}]$} & BOE 183/1953, 2-07 (4010-4012) "Ed. física”, 3 h/sem x 6 cursos. \\
\hline$\square$ & 4. D 31-05-1957 & {$[\mathrm{MEN}]$} & $\begin{array}{ll}\text { BOE 158/1957, 18-06 (437-438) } \begin{array}{l}\text { "Ed. Física y Deportiva", 3h/sem x } \\
2 \mathrm{~h} / \text { sem x 6. }{ }^{\circ} \text { curso. }\end{array}\end{array}$ \\
\hline$\Gamma$ & 5. L 16/1967, 8-04 & [JE] & BOE 86/1967, 11-04 (4805-4806) [Unifica Bachilleratos Elementales.] \\
\hline 0 & 6. D 1106/1967, 31-0518 & 8 [MEN] & BOE 131/1967, 2-06 (7524-7526) "Ed. Física y Deportiva", 3h/sem x 4 cursos. \\
\hline
\end{tabular}

En general, cabe reconocerle al franquismo esfuerzos prácticos por difundir este nivel de estudios; además de la creación del Bachillerato Laboral, se aumentó significadamente el número de Centros de Bachillerato (secciones) y se regularon los estudios nocturnos para jóvenes trabajadores.

En la etapa altofranquista debemos mencionar además la normativa que dio origen a un experimento docente al que el Régimen dedicó especial atención, cual es el de las Universidades Laborales, centros superiores de formación profesional organizados por el Ministerio de Educación pero subvencionados por el Ministerio de Trabajo, en los que, además de los tipos de estudios de formación profesional, se podía cursar el Bachillerato Laboral y el Período de Iniciación Profesional de la Educación Primaria. En las Universidades Laborales, que se crearon en los años cincuenta ${ }^{19}$ y se desarrollaron con gran efectividad hasta la Transición política, se aplicaban los mismos planes de estudios que en los demás centros, con la salvedad de que en sus dependencias tenían residencias de internado para escolares de otras poblaciones y un equipamiento destacado para la práctica de actividad física, tanto escolar como extraescolar.

18 Corrección de errores, BOE, 148/1967, de 22 junio, 8.681, y BOE, 163/1967, de 10 julio, 9.670.

${ }^{19}$ Ley de 20 de julio de 1955 sobre «Formación Profesional Industrial» [JE] (BOE, 202/1955, de 21 julio, 4.4424.453). 
Tabla 5

Planes de estudio del Bachillerato laboral durante el altofranquismo (1936-1970)

\begin{tabular}{|c|c|c|c|c|}
\hline \multicolumn{5}{|c|}{$\begin{array}{l}\text { Tabla } 5 \\
\text { Planes de estudios del Bachillerato laboral durante el altofranquismo (1936-1970) } \\
\text { aboral (BLE= Elemental; BLS= Superior), } \Delta \text { Plan de adaptación, OBachillerato laboral femenino } \\
\text { Véanse las claves de normas, organismos y publicaciones al inicio del artículo }\end{array}$} \\
\hline $\mathrm{N}^{\circ}$ Norma y fecha & [Organismo] & Publicación & (Págs.) & Afectaciones a educación física \\
\hline$\diamond 1 . \mathrm{L} 16-07-1949$ & [JE] & $\begin{array}{l}\text { BOE } 198 / 1949,17- \\
07\end{array}$ & $3164-31$ & Incluye la materia de educación física. \\
\hline$\diamond$ 2.D 24-03-1950 & {$[\mathrm{MEN}]$} & $\begin{array}{l}\text { BOE } 102 / 1950,12- \\
04\end{array}$ & $1576-15$ & “Educación Física” x 5 cursos. \\
\hline$\diamond 3 . D \quad 6-07-1956$ & [MEN] & $\begin{array}{l}\text { BOE 224/1956, 11- } \\
08\end{array}$ & $242-52$ & No se alude. \\
\hline$\diamond 4 . \mathrm{D} 21-12-1956$ & {$[\mathrm{MEN}]$} & $\begin{array}{l}\text { BOE } 24 / 1957,24- \\
01\end{array}$ & (403-406) & $\begin{array}{l}\text { BLE, "Educación Física" x } 5 \text { cursos; } \\
\text { BLS, "Educación física" x } 2 \text { cursos. }\end{array}$ \\
\hline$\Delta \quad 5 . \mathrm{O} \mathrm{24-04-1957}$ & [MEN] & $\begin{array}{l}\text { BOE } 127 / 1957,13- \\
05\end{array}$ & $(238-239)$ & "Educación Física", 30 min/día x 6 días. \\
\hline 6.D 23-08-1957 & [MEN] & $\begin{array}{l}\text { BOE } 237 / 1957,18- \\
09\end{array}$ & $(886-887)$ & "Educación Física” x 5 cursos. \\
\hline$\diamond 7 . D \quad 5-09-1958$ & [MEN] & $\begin{array}{l}\text { BOE } 237 / 1958,3- \\
10\end{array}$ & $(1718-17$ & $\begin{array}{l}\text { ) BLE= "Educación Física" x } 5 \text { cursos; } \\
\text { BLS = "Educación Física" + "F.E.N."+ } \\
\text { "Enseñanzas de Hogar", } 2 \text { h/sem x } 2 \text { cursos. }\end{array}$ \\
\hline$\Delta 8.018-06-1959$ & {$[\mathrm{MEN}]$} & $\begin{array}{l}\text { BOE 208/1959, 31- } \\
08\end{array}$ & $(11550-115$ & $\begin{array}{l}\text { ) Se desarrollarán semanalmente las prácticas de } \\
\text { "Educación Física"... necesarias. }\end{array}$ \\
\hline$\diamond 9.08-07-1960$ & [MEN] & $\begin{array}{l}\text { BOE } 179 / 1960,27- \\
07\end{array}$ & $10447-104$ & BLS= No contempla. \\
\hline$\diamond 10.08-07-1960^{20}$ & [MEN] & $\begin{array}{l}\text { BOE } 199 / 1960,19- \\
08\end{array}$ & $1726-117$ & SLS= No contempla. \\
\hline$\diamond 11.026-07-1960$ & [MEN] & $\begin{array}{l}\text { BOE } 197 / 1960,17- \\
08\end{array}$ & $1613-116$ & BLS= No contempla. \\
\hline$\nabla 12.012-09-1963$ & [MEN] & $\begin{array}{l}\text { BOE } 245 / 1963,12- \\
10\end{array}$ & $(14624-146$ & 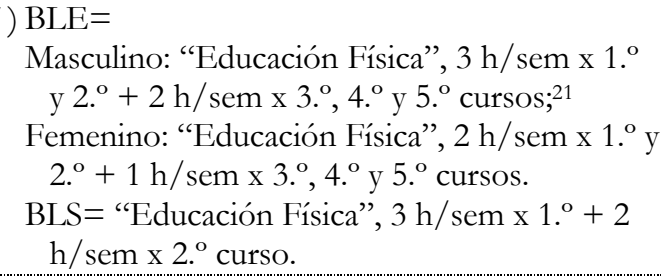 \\
\hline$\diamond 13 . \mathrm{O} \quad 6-07-1964$ & [MEN] & $\begin{array}{l}\text { BOE } 195 / 1964,14- \\
08\end{array}$ & $10696-107$ & $\begin{array}{l}\text { BLS }=\text { "Educación Física", } 3 \mathrm{~h} / \mathrm{sem} \times 10^{\circ}+2 \\
\mathrm{~h} / \mathrm{sem} \times 2 .^{\circ} \text { curso. }\end{array}$ \\
\hline 14.O 31-07-1964 & {$[\mathrm{MEN}]$} & $\begin{array}{l}\text { BOE } 197 / 1964,17- \\
08\end{array}$ & $10789-107$ & $\begin{array}{l}\text { BLE = "Educación Física", } 3 \mathrm{~h} / \mathrm{sem} \text { x } 10^{\circ} \text { y } 2^{\circ} \\
+2 \mathrm{~h} / \mathrm{sem} \times 30^{\circ}+1 \mathrm{~h} / \mathrm{sem} \times 40^{\circ} \text { y } 5^{\circ} \text { cursos. }\end{array}$ \\
\hline
\end{tabular}

\subsubsection{Aspectos de educación física}

Encontramos en las enseñanzas medias del altofranquismo una amplia prescripción de horarios para la asignatura, que en general siguen estas pautas:

- De planteamientos iniciales que la contemplan diariamente en todos los cursos, las sucesivas reformas disminuyen la dedicación semanal e incluso, a veces, el número de cursos.

${ }^{20}$ Es Orden diferente de la anterior, a pesar de llevar la misma fecha.

${ }^{21}$ Horarios de Educación Física para las especialidades masculinas modificados por Orden de 11 de diciembre de 1963 [MEN] (BOE, 312/1963, de 30 diciembre, 18.200-18.201). 
- Se plantean siempre mayores asignaciones horarias en los bachilleratos elementales que en los superiores.

- Los planes de los alumnos tienen mayores asignaciones que los de las alumnas, debido a la obligatoriedad de que éstas cursaran asignaturas "femeninas", ${ }^{22}$ cuya dedicación horaria se hacía generalmente a costa de la educación física.

\section{Valoración y conclusiones}

\subsection{Las denominaciones de una asignatura}

En la tabla 6 he resumido la evolución cronológica de las denominaciones de las asignaturas de educación física en los planes que las contemplaban dentro del período estudiado: encontramos hasta diez denominaciones que, salvo "Educación física" y "Educación física y deportiva" no coinciden cronológicamente de un nivel a otro.

Como vemos, en la Enseñanza primaria se utilizan cuatro denominaciones: "Ejercicios corporales" (1901), "Paseos y excursiones" (1918 y 1934, siempre en forma de recomendaciones para su práctica), "Educación física y deportiva" (1965, niños), y la más frecuente, "Educación física", a partir de 1937.

Tabla 6

Evolución de la denominación de las asignaturas de educación física en los planes de estudios de dos niveles educativos (1857-1970)

\begin{tabular}{|c|c|c|c|c|}
\hline \multicolumn{5}{|c|}{$\begin{array}{c}\text { Tabla } 6 \\
\text { Evolución de la denominación de las asignaturas de educación física } \\
\text { en los planes de estudios de dos niveles educativos (1857-1970) } \\
\text { Cada año representa una modificación de plan de estudios }\end{array}$} \\
\hline \multirow{2}{*}{ Denominación de la asignatura } & \multicolumn{4}{|c|}{ Planes de estudios: } \\
\hline & Primaria & & Bachillera & rato \\
\hline 1. Gimnástica higiénica & & 1873 & & \\
\hline 2. Gimnasia & & $\begin{array}{l}1894 \\
1900 \\
1932\end{array}$ & 19011 & $1903^{1899}$ \\
\hline 3. Gimnástica & & 1893 & 18951 & 18961898 \\
\hline 4. Juegos y ejercicios corporales & & & & 1901 \\
\hline 5. Ejercicios corporales & 1901 & & & \\
\hline 6. Paseos y excursiones & $\begin{array}{l}1918 \\
1934\end{array}$ & 1926 & & \\
\hline 7. Educación física & $\begin{array}{cc}1937 \\
1938 & 1945 \\
1965 & \text { (niñas) }\end{array}$ & $\begin{array}{c}1926^{23} \\
1932\end{array}$ & & 19381953 \\
\hline 8. Juegos deportivos & & 1926 & & \\
\hline 9. Juegos y deportes & & & $1934^{24}$ & \\
\hline 10. Educación física y deportiva & 1965 (niños) & & & 19571967 \\
\hline
\end{tabular}

${ }^{22}$ Galera Pérez, Antonio D., Las "disciplinas del Movimiento"...

${ }^{23}$ Durante todos los cursos se practicarán diariamente ejercicios de educación física, paseos y juegos deportivos, sin que estas prácticas lleguen a constituirse como asignatura (Real Decreto de 25-08-1926 y Real Orden de 309-1926).

${ }^{24}$ Sin consideración de asignatura (Decreto de 29-08-1934). 


\begin{tabular}{|c|c|c|}
\hline \multicolumn{3}{|c|}{$\begin{array}{l}\text { Tabla } 6 \\
\text { Evolución de la denominación de las asignaturas de educación física } \\
\text { en los planes de estudios de dos niveles educativos (1857-1970) } \\
\text { Cada año representa una modificación de plan de estudios }\end{array}$} \\
\hline \multirow{2}{*}{ Denominación de la asignatura } & \multicolumn{2}{|c|}{ Planes de estudios: } \\
\hline & Primaria & Bachillerato \\
\hline Total denominaciones asignatura & 4 & 9 \\
\hline
\end{tabular}

Por su parte, en el Bachillerato se utilizaron nueve denominaciones: la primera, "Gimnástica higiénica" (1873), la segunda y más frecuente, por el número de reformas de que fue objeto, "Gimnasia" (1894, 1899, 1900, 1901, 1903, y 1932, en uno de los planes republicanos), la tercera, "Gimnástica” (1893, 1895, 1896, 1898), una efímera, de 1901 ("Juegos y ejercicios corporales", quizá por equiparación con la de "Ejercicios corporales" de la reforma de Enseñanza primaria del mismo año), "Paseos y excursiones" (como parte del plan de estudios de 1926), "Educación física" (presente en los tres períodos histórico-educativos: 1926, 1932, y 1938-1965), "Juegos deportivos" (1926), "Juegos y deportes" (1934), y "Educación física y deportiva" (1957 y 1967).

4.2. La atención diferencial a la Segunda Enseñanza

La comparación de las tablas de resumen que anteceden es suficientemente explícita: hasta 1970, los planes de estudios de la enseñanza primaria no han suscitado en España un interés siquiera discreto, lo cual es lógico desde un punto de vista puramente normativo; la legislación no hacía más que reflejar una concepción político-social, por lo que las sucesivas reformas, abundantes y frecuentes en la enseñanza secundaria, no alcanzaban a la primaria: en la concepción global del sistema educativo liberal, aquélla no se nutría de ésta. Así, entre 1857 y 1931 encontramos hasta 20 reformas del Bachillerato, frente a únicamente tres de la Primera enseñanza (cuatro, si contamos la reforma fallida de 1868).

Durante la II República, siempre dentro de esta tendencia a regular con mayor atención la Segunda que la Primera enseñanza, se promulgaron hasta cuatro planes de estudios de Bachillerato frente a uno de Primera enseñanza, bien es cierto que éste con una gran calidad (1937), aunque no pudo llevarse a cabo por el desenlace de la Guerra Civil.

En el altofranquismo, que se aplica a la reforma de las Enseñanzas medias ya en la propia Guerra Civil, volvemos a encontrar un elevado número de planes de Bachillerato, también 20 reformas, y una única reforma general de la Enseñanza Primaria (1945), actualizada en algunos aspectos en 1965.

En la tabla 7 vemos que la suma de las 50 reformas de los Bachilleratos (36 del general, 14 del laboral) multiplica por casi 4 las de la Educación primaria $(50 / 14=3,5)$ en el total del período estudiado.

Tabla 7

Reformas de planes de estudios (1857-1970)

\begin{tabular}{|l|c|c|c|}
\hline \multicolumn{3}{|c|}{ Tabla 7: } \\
\begin{tabular}{|l|l|} 
Reformas de planes de estudios (1857-1970) \\
EP= Ed. primaria \\
BL= Bachillerato general \\
BLachillerato laboral
\end{tabular} \\
\hline Período & EP & B & BL \\
\hline \hline I Restauración & 4 & 20 & \\
\hline II República & 4 & 10 & \\
\hline Altofranquismo & 6 & 6 & 14 \\
\hline Total reformas & 14 & 36 & 14 \\
\hline
\end{tabular}




\subsection{La importancia de la educación física en el altofranquismo}

Respecto de la educación física, podemos resaltar su sistemática prescripción normativa durante el franquismo, tanto en la Enseñanza Primaria como en las Enseñanzas Medias, que parte de elevadas dedicaciones horarias en todos los planes de estudios, recomendaciones utópicas que con el tiempo se van atemperando a valores más realistas. No obstante, el plan en que mejor se reguló la docencia de esta materia fue el republicano de 1937, que prescribía asimismo elevados valores de dedicación horaria, al tiempo que orientaciones pedagógicas generales en que estaban presentes aspectos de educación física que conferían gran valor didáctico a la práctica escolar.

En las tablas que siguen he sintetizado la evolución de la presencia de la educación física en los dos niveles educativos estudiados, durante los tres períodos histórico-educativos que hemos diferenciado en esta investigación: liberalismo (1857-1931), II República (1931-1939), y altofranquismo (1936-1970).

En el liberalismo (tabla 8) observamos la importancia que la legislación concede al Bachillerato (20 reformas) frente a la Instrucción primaria (4 "reformas", de las que una no se llegó a aplicar en la práctica, 1868, y la otra es una simple recomendación de prácticas de educación física en forma de paseos y excursiones, 1918). En un total de 23 reformas (24, si contamos como dos las respectivas omisiones de la educación física en la Ley Moyano), comienzan a aparecer asignaturas de educación física a partir de las reformas número 6 (Primera enseñanza, 1868), y número 8 (Bachillerato, 1873), ninguna de las cuales se llegó a aplicar. Habrá que esperar hasta 1893 (Bachillerato) y 1901 (Instrucción primaria) para empezar a ver continuidad en la prescripción de asignaturas de educación física en la legislación española.

Tabla 8

Planes de estudio del liberalismo (1857-1931): Presencia de educación física

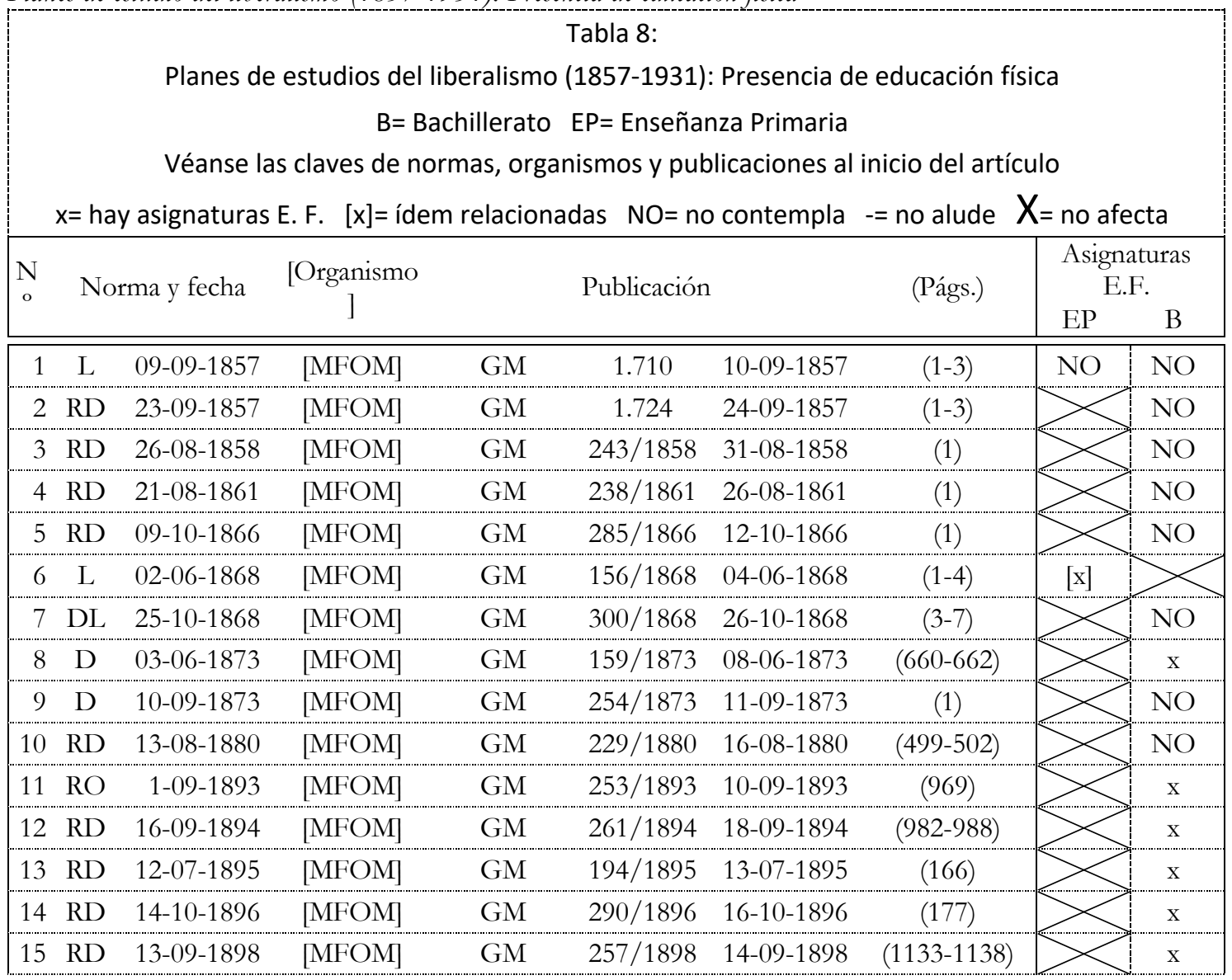




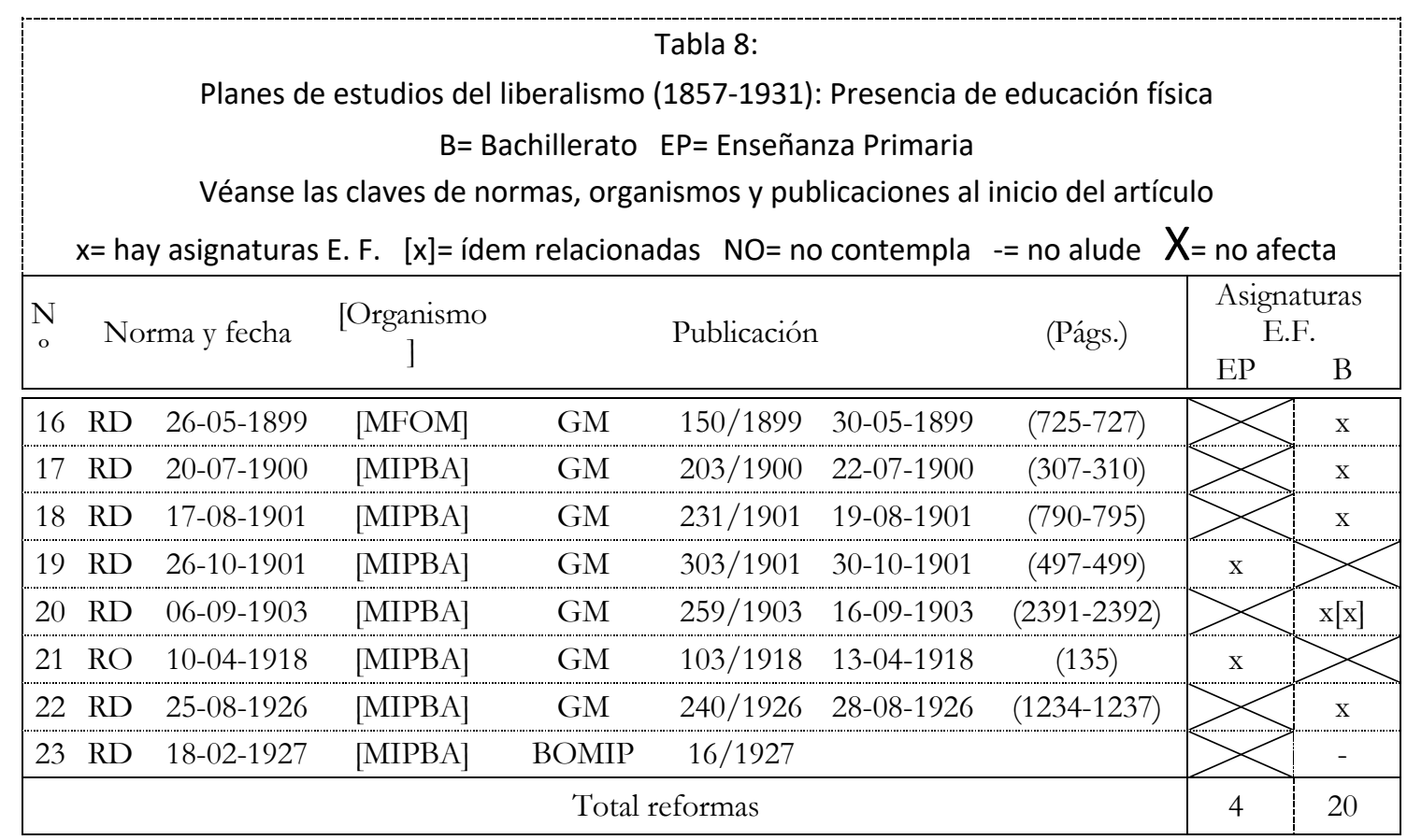

En la II República (tabla 9) se acometen hasta 10 reformas del Bachillerato, frente a 4 de la Instrucción Primaria, con presencia fluctuante de la educación física, muy presente en algunos planes como el de las Escuelas primarias de 1937, o no contemplada en muchos de los demás.

Tabla 9

Planes de estudios de la II República (1931-1939): Presencia de educación física

\begin{tabular}{|c|c|c|c|c|c|c|c|c|}
\hline$x=$ hal & $\begin{array}{l}\text { Planes de e } \\
\text { Véanse las } \\
\text { asignaturas }\end{array}$ & $\begin{array}{l}\text { tudios de la II } \\
\qquad \mathrm{B}=\mathrm{Bac} \\
\text { claves de norn } \\
\text { F. }[\mathrm{x}]=\text { ídem }\end{array}$ & $\begin{array}{l}\text { epúblic } \\
\text { Ilerato } \\
\text { elacion orga }\end{array}$ & $\begin{array}{l}\text { Tabla 9: } \\
\text { (1931-193 } \\
\text { EP= Enseña } \\
\text { ismos y pu } \\
\text { das NO=n }\end{array}$ & $\begin{array}{l}\text { : Presencia } \\
\text { za Primaria } \\
\text { licaciones al } \\
\text { contempla }\end{array}$ & $\begin{array}{l}\text { de educación fi } \\
\text { inicio del artícu } \\
\text {-= no alude }\end{array}$ & & \\
\hline $\mathrm{N}^{\mathrm{o}}$ & cma y fecha & [Organismo] & & Publicaci & & (Págs.) & & $\begin{array}{l}\text { turas } \\
\text {. }\end{array}$ \\
\hline 1. D & 06-05-1931 & [MIPBA] & GM & $129 / 1931$ & 09-05-1931 & $(619-620)$ & & \\
\hline 2. $\mathrm{D}$ & 13-05-1931 & [MIPBA] & GM & $134 / 1931$ & $14-05-1931$ & $(717)$ & & $\mathrm{x}[\mathrm{x}]$ \\
\hline 3. $\mathrm{O}$ & 13-07-1932 & [MIPBA] & GM & $200 / 1932$ & $18-07-1932$ & $(410-411)$ & & $\mathrm{x}[\mathrm{x}]$ \\
\hline 4. $\mathrm{O}$ & 21-09-1932 & [MIPBA] & GM & $266 / 1932$ & 22-09-1932 & (2115) & & $\mathrm{x}$ \\
\hline 5. D & 14-08-1933 & [MIPBA] & GM & $228 / 1933$ & $16-08-1933$ & (1082) & & $\mathrm{x}$ \\
\hline 6. $\mathrm{O}$ & 27-09-1933 & [MIPBA] & GM & $272 / 1933$ & 29-09-1933 & (1948) & & - \\
\hline 7. $\mathrm{O}$ & 21-03-1934 & [MIPBA] & GM & $91 / 1934$ & 01-04-1934 & $(12-13)$ & & - \\
\hline 8. $\mathrm{O}$ & 20-07-1934 & [MIPBA] & GM & $202 / 1934$ & 21-07-1934 & $(725)$ & & - \\
\hline 9. OC & 08-08-1934 & [MIPBA] & GM & $221 / 1934$ & 09-10-1934 & (1389) & x] & \\
\hline 10. D & 29-08-1934 & [MIPBA] & GM & $242 / 1934$ & $30-08-1934$ & $(1871-1874)$ & & $\mathrm{x}$ \\
\hline 11. D & 23-03-1935 & [MIPBA] & GM & $85 / 1935$ & 26-03-1935 & (2381) & & - \\
\hline 12. D & 21-11-1936 & [MIPBA] & GM & $328 / 1936$ & 23-11-1936 & $(769)$ & & $\mathrm{NO}$ \\
\hline
\end{tabular}




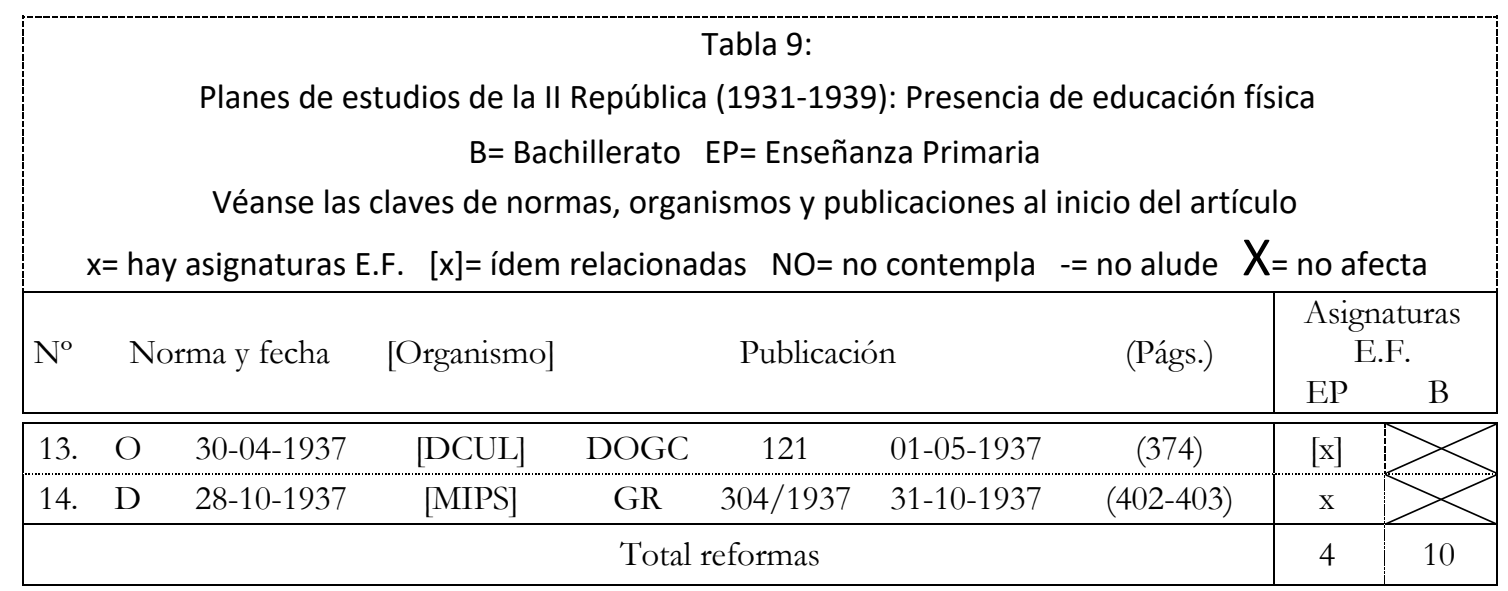

Por su parte, el altofranquismo (tabla 10) promulgó numerosas reformas del Bachillerato, estableciendo una rama laboral con 14 variaciones de los planes de estudio; en Enseñanza primaria podemos hablar en realidad de 2 planes de estudios (1945 y 1965), pues el resto de reformas son especificaciones parciales de algunos aspectos, entre las que a veces está la educación física (1938 y dos de 1941), y otras, no (1936).

Tabla 10

Planes de estudios del altofranquismo (1936-1970): Presencia de educación física

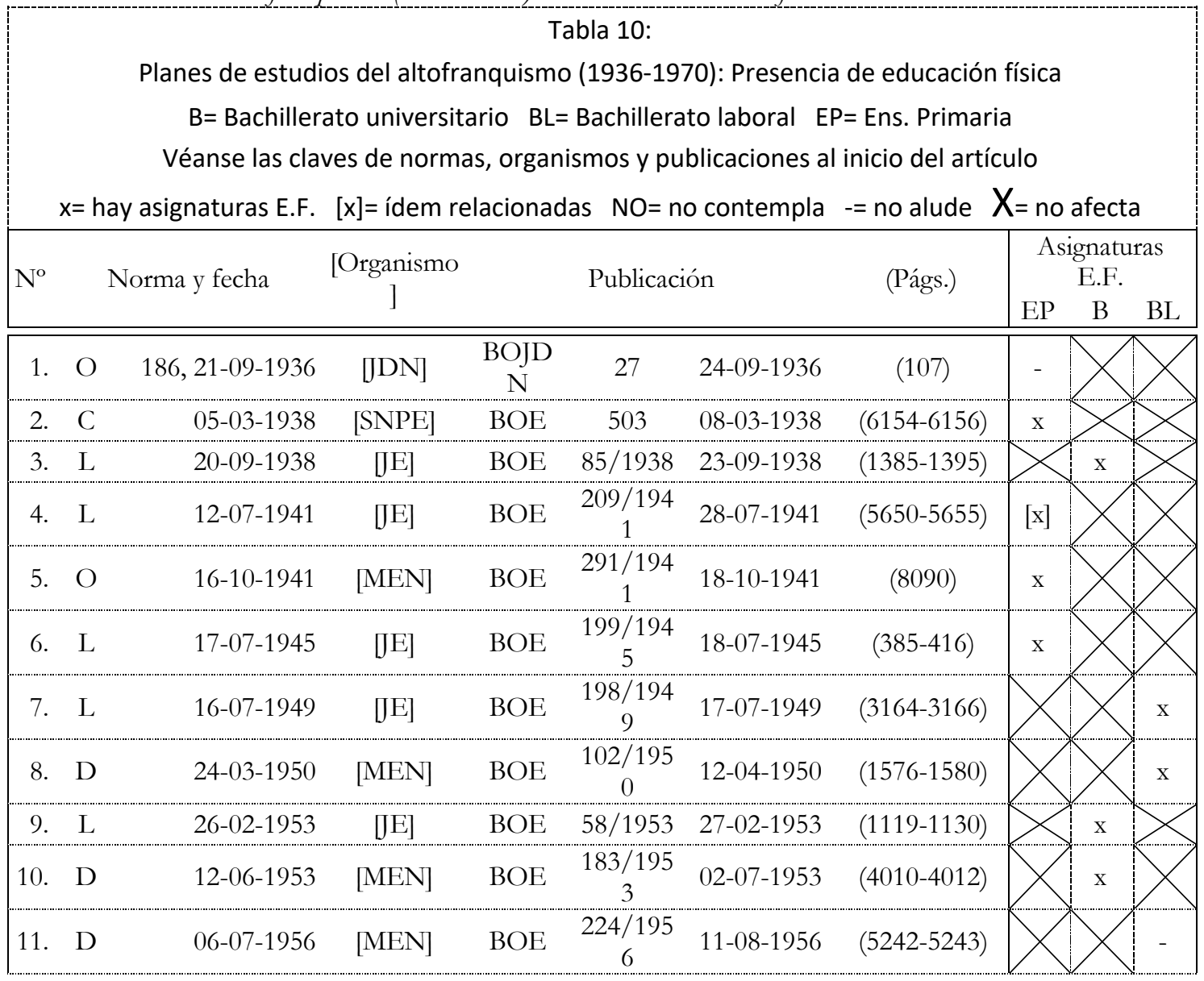




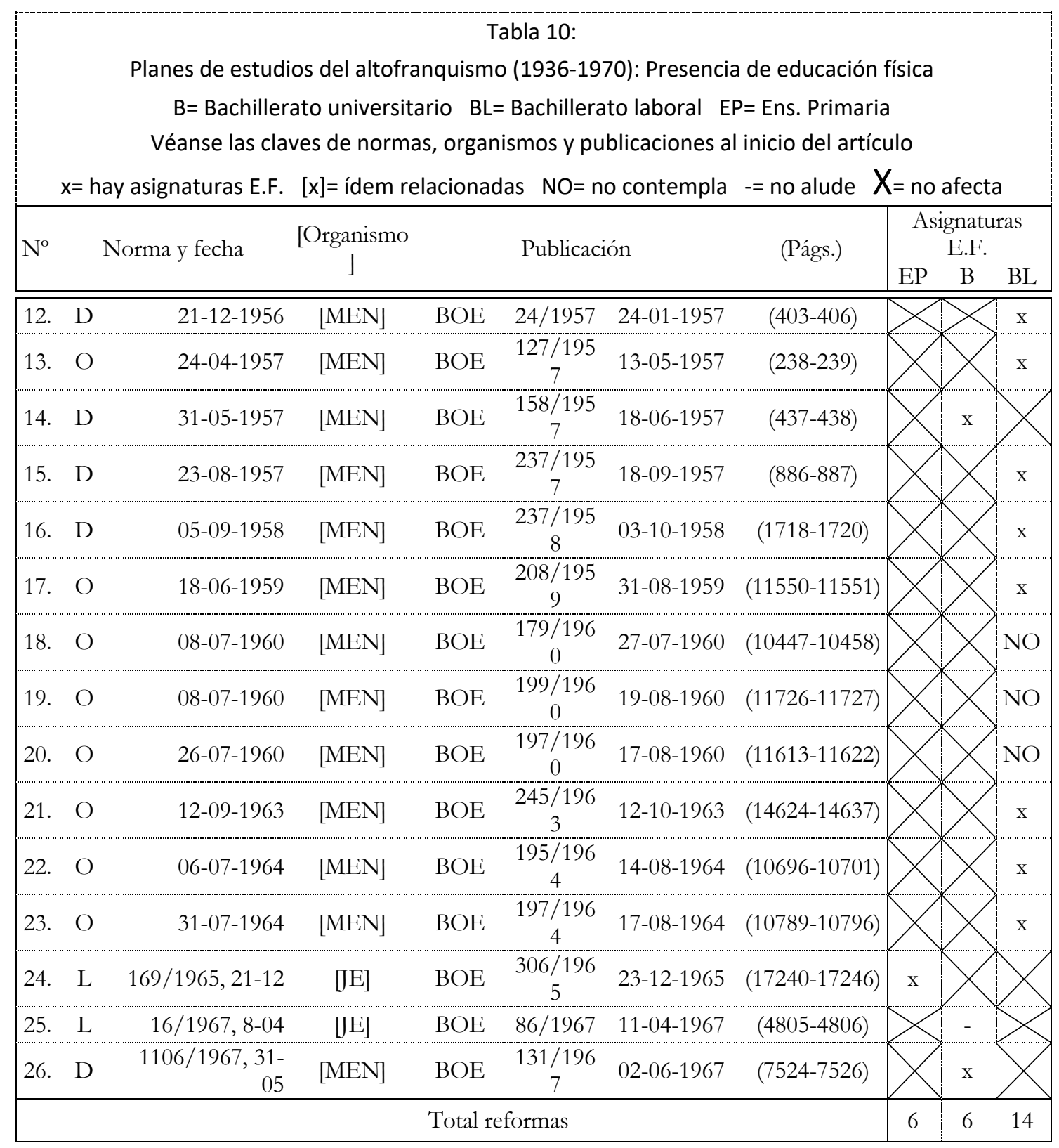

\section{A modo de síntesis}

De la comparación entre las tres tablas que anteceden extraemos la tabla 11, que nos muestra, por un lado, la atención que durante todo el período estudiado se dedica a la Enseñanza secundaria: 49 reformas, frente a las escasas 14 de la primaria. Convertida ésta en una 'vía muerta', en la que los escolares se veían precisados a elegir a los 10 años entre seguir estudiando o trabajar, y, en el mejor de los casos, únicamente trabajar a los 12 años ${ }^{25}$, vemos confirmada la opinión del Dr. Ávila de que

25 Galera Pérez, Antonio D. (2018). Escuela pública durante la I Restauración (1875-1931): Aspectos administrativos y curriculares. Cabás: Revista del Centro de Recursos, Interpretación y Estudios en materia educativa (CRIEME) de la Consejería de Educación, Cultura y Deporte del Gobierno de Cantabria (España) [en línea], 19, junio, 17-42. Recuperado de http://revista.muesca.es/articulos19/425-escuela-restauracion. 
«las distintas Reformas educativas han producido más segregación que consolidación.» ${ }^{26}$ Siendo el Bachillerato la 'verdadera educación', era en este nivel en el que se centraba la atención de la persona legisladora, para imponer en él la ideología política de turno, multiplicando unas reformas que no pocas veces diferían única y precisamente en un aspecto marginal para el sistema: el tratamiento que se daba a la educación física.

Una segunda observación que podemos efectuar de la tabla 11 es la atención que el altofranquismo dedicó a la presencia de la educación física en sus planes de estudios, en todos los niveles analizados: de un 58-57 por ciento de promedio de planes con presencia de educación física durante el Liberalismo y la II República, pasamos a un 77 por ciento (gráfica 1). Pero esta atención no tenía una finalidad inicialmente educativa, sino política: incardinar a la juventud, y una vez más, con preferencia a la que nutría los estudios de Bachillerato, en un orden social determinante, que no en vano la asignatura estaba incluida entre las 'disciplinas del Movimiento'. ${ }^{27}$

A ambas observaciones cabe añadir el colofón de una deficiente formación en educación física de los maestros y maestras de Enseñanza primaria, ${ }^{28}$ lo que confirma el desentendimiento de la Administración por este nivel y por la propia asignatura en tanto que susceptible de acción educativa propiamente dicha.

Tabla 11

Presencia de educación física en los planes de estudios (1857-1970). Porcentaje de planes con asignaturas de educación física

\section{Tabla 11:}

Presencia de educación física en los planes de estudios (1857-1970)

Porcentaje de planes con asignaturas de educación física Claves: $\mathrm{dR}=$ densidad reformatoria
(a) Liberalismo
(b) II República
(c) Altofranquismo

(1857-1931) [74 años] (1931-1939) [8 años] (1936-1970) [34 años]

\begin{tabular}{|cr|c|c|c|c|}
\hline Nivel & Parámetro & (a) & (b) & (c) \\
\hline \hline Ed. Primaria & Reformas & 4 & 4 & 6 \\
& Presencia EF & 3 & 3 & 5 \\
& $\% \mathrm{EF}$ & $75 \%$ & $75 \%$ & $83 \%$ \\
\hline Bachillerato general & $\mathrm{dR}$ & 0,27 & 2,50 & 0,88 \\
& Reformas & 20 & 10 & 6 \\
& Presencia EF & 11 & 5 & 5 \\
& $\% \mathrm{EF}$ & $55 \%$ & $50 \%$ & $83 \%$ \\
\hline Bachillerato laboral & $\mathrm{dR}$ & 1,35 & 6,25 & 0,88 \\
& Reformas & & & 14 \\
& Presencia EF & & & 10 \\
& $\% \mathrm{EF}$ & & & $71 \%$ \\
\hline $\mathrm{dR}$ & & & 2,06 \\
\hline Promedios & $\% \mathrm{EF}$ & $58 \%$ & $57 \%$ & $77 \%$ \\
\hline $\mathrm{dR}$ & 1,62 & 8,75 & 3,82 \\
\hline
\end{tabular}

26 Ávila Fernández, Alejandro. (2004). ¿Para qué tanta reforma educativa? Revista Fuentes, Sevilla, 5, 4. Recuperado de https://revistascientificas.us.es/index.php/fuentes/article/view/2404.

${ }^{27}$ Galera Pérez, Antonio D., Las “disciplinas del Movimiento"...

${ }^{28}$ López Fernández, Iván (2003). Evolución histórica de la formación inicial del profesorado de Educación Física en España. Revista Fuentes, Sevilla, 4. Recuperado de https://revistascientificas.us.es/index.php/fuentes/article/view/2435. 
Para terminar, si se nos permite introducir el neologismo de 'densidad reformatoria', asimilándolo al del número de reformas habidas en un quinquenio, obtenemos en dicha tabla el parámetro dR:

$$
\mathrm{dR}=\text { Reformas } / \text { Años * } 5
$$

En el que Reformas $=$ número de reformas de los planes de estudios

Años= número de años de vigencia del período político-administrativo estudiado.

Como podemos comprobar en dicha tabla 11 y en la gráfica 2, en los dos niveles estudiados destaca la acción reformadora de la II República ( $\mathrm{dR}=8,75$ reformas, de las que 6,25 corresponden al Bachillerato), y luego el altofranquismo ( $\mathrm{dR}=3,82$ reformas, de las que 2,06 corresponden al nivel del Bachillerato laboral.

Otra cosa sería averiguar las justificaciones de dichas reformas, que en cada período respondieron a causas bien diferentes. Pero eso sería asunto de ulteriores consideraciones.

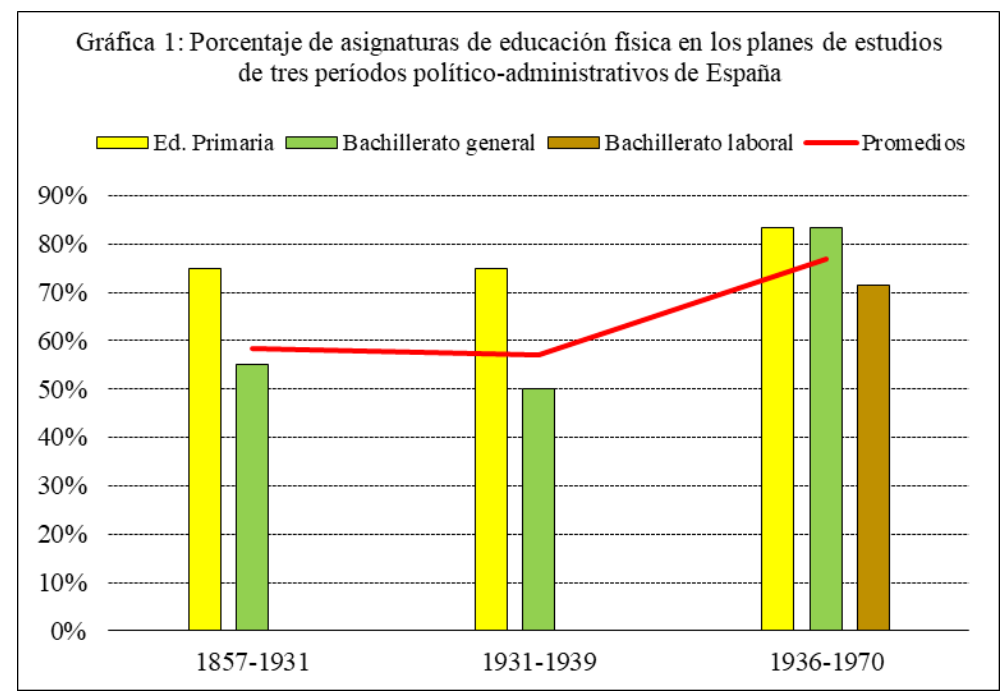

Gráfica 1. Porcentaje de asignaturas de educación física en los planes de estudios de tres períodos político-administrativos de España

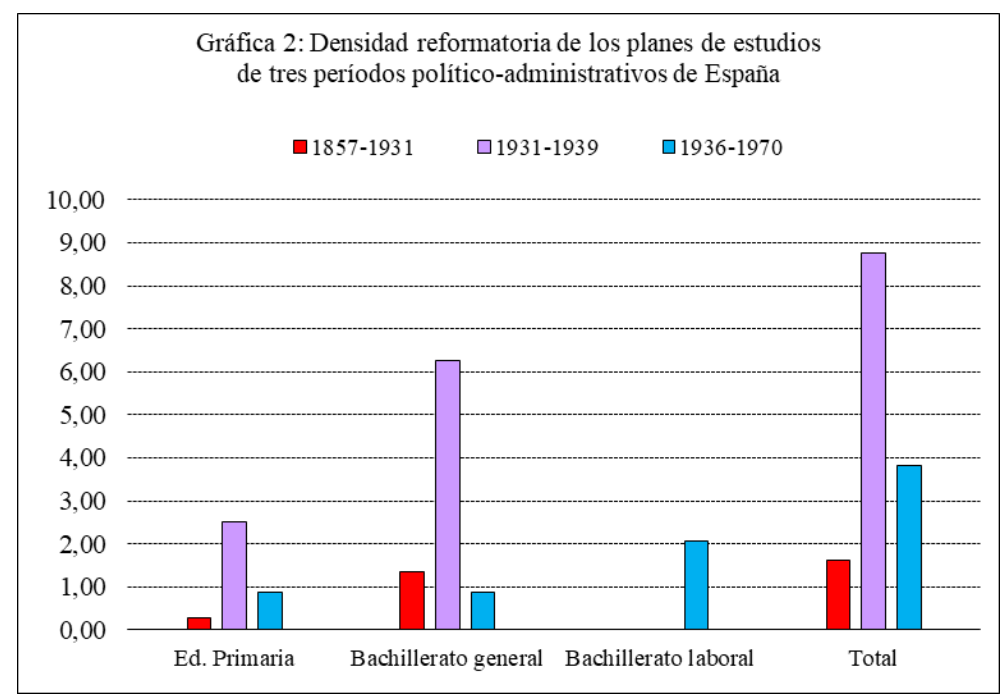

Gráfica 2. Densidad reformatorio de los planes de estudios de tres períodos políticoadministrativos de España. 


\section{Referencias bibliográficas}

Los datos de publicación de cada plan de estudios han sido extraídos de las respectivas disposiciones legales, localizadas a través de las bases de datos del Boletín Oficial del Estado, el portal WestlawAranzadi, el Ministerio de Educación o, supletoriamente, de algunas publicaciones oficiales (en su mayoría, el Boletín Oficial del Ministerio encargado de la educación en cada período).

Algunas personas además han acometido en ocasiones el estudio histórico normativo de la educación física en los planes de estudios, generalmente limitados a un nivel educativo o desde perspectivas generales; sus principales referencias son las que siguen.

\section{Síntesis generales}

Asensio Domínguez, Jn Ignacio (1983). Un siglo de legislación de la Educación Física. Madrid: Instituto Nacional de Educación Física. [Tesina fin de carrera, director, José María Cagigal Gutiérrez.]

Bolea Nueno, Ángel (1983). La enseñanza de la Educación Físico-Deportiva en la legislación española hasta la Ley 13/1980. En I Simposio Nacional 'El deporte en la sociedad española contemporánea'. Madrid, 23 a 25 de noviembre de 1983, vol. VI. Madrid: Consejo Superior de Deportes, Instituto de Ciencias de la Educación Física y el Deporte.

Bravo Berrocal, Rafael (1995). La Educación Física en la legislación española (1900-1980). Málaga: Ágora.

Cambeiro Martínez, Juan A. (1997). El proceso de institucionalización de la educación física en la España contemporánea. Barcelona: Universitat de Barcelona, Dep. Teoria i Història de l'Educació. [Tesis doctoral dirigida por Dr. Conrad Vilanou Torrado.]

Lucas Heras, J. M $\mathrm{M}^{\mathrm{a}}$ de (2000). Historia de la Educación Física Oficial. España 1900-1936. Guadalajara: Universidad de Alcalá, 2000.

Mendiágara Callén, Natividad (1986). Análisis de la Educación Física femenina en el sistema educativo español. Pasado, presente y futuro. En Seminario "Deporte y Mujer". Madrid: Inst. Ciencias de la Educación Física y el Deporte / Inst. de la Mujer.

Plana Galindo, Carlos (1996). La Educación Física en España durante las últimas décadas del siglo XIX. En Actas del III Congreso Nacional de Educación Física de Facultades de Ciencias de la Educación y XIV de Escuelas Universitarias de Magisterio (317-322). Guadalajara: Universidad de Alcalá.

Plana Galindo, Carlos y Casterad Seral, J. (1996). La Educación Física en España durante el primer tercio del siglo XX (1900-1937). En Actas del III Congreso Nacional de Educación Física de Facultades de Ciencias de la Educación y XIV de Escuelas Universitarias de Magisterio (63-71). Guadalajara: Universidad de Alcalá.

Rodríguez Huerta, M. A. (1985). Pequeños apuntes de legislación española sobre E. Física en el siglo XIX. Revista Española de Educación Física y Deportes, Madrid, núm. 6 (noviembre-diciembre), 32.

\section{Monografías sobre Enseñanza primaria}

Civila Salas, Amparo Consuelo (1996). Rápido recorrido por los contenidos de la enseñanza obligatoria: desde la Constitución de 1812 hasta la L.O.G.S.E. En 'El currículum: Historia de una mediación social y cultural'. Actas del IX Coloquio de Historia de la Educación (249-258). Granada: Universidad de Granada / I. C. E.

Egido Gálvez, Inmaculada (1994). La evolución de la Enseñanza Primaria en España: Organización de la etapa y programas de Estudio. Tendencias, Universidad Autónoma de Madrid, núm. 1, 7586.

Iniesta, Alfredo (1951). Medio siglo de Enseñanza primaria. Bordón, Madrid, vol. III, núm. 17-18 (enero-febrero), 44-60.

López del Castillo, $\mathrm{M}^{\mathrm{a}}$ Teresa (1982). Planes y programas escolares en la legislación española. Bordón, Madrid, tomo XXXIV, núm. 242-243 (marzo-junio), 127-202.

Martínez Navarro, Anastasio (1996). Juegos y deportes como innovación curricular en los programas españoles de Educación Física escolar, anteriores a la L. G. E. En 'El currículum: Historia de una 
mediación social y cultural', Actas del IX Coloquio de Historia de la Educación (tomo I, 99-107). Granada: Universidad de Granada / I. C. E.

Martínez Navarro, Anastasio (1997). La educación física escolar en España. Hitos históricos. Madrid: Universidad Complutense [ISBN: 84-8498-650-0.]

Pajarón Sotomayor, Rocío (1989). La Educación Física en la legislación de Primera Enseñanza española del siglo XIX. Bordón, Madrid, volumen 41, núm. 2, 345-353.

Pajarón Sotomayor, Rocío (1995-1996). La E.F. en la legislación escolar franquista, 1938-1970. Historia de la Educación, Salamanca, Universidad de Salamanca, núm. 14-15, 469-480.

Pajarón Sotomayor, Rocío (2001). La educación física escolar en España en la primera mitad del siglo XX. Madrid: Universidad Complutense de Madrid, Facultad de Educación, Departamento de Teoría e Historia de la Educación. [Tesis doctoral dirigida por Dra. Carmen Labrador Herráiz.]

Pedrero Guzmán, $\mathrm{M}^{\mathrm{a}}$ Carmen (1991). La Educación Física en la enseñanza primaria. Estudio de su evolución bistórica a través de las disposiciones legales. Esplugues de Llobregat (Barcelona): INEFC. [Tesina de licenciatura].

Zapico García, José Mª (1997). Historia y evolución del diseño curricular español en la Educación Física escolar. En García Blanco, Saúl (coord.), IV Simposium (sobre) Historia de la Educación Física (117-162). Salamanca: Servicio de Educación Física y Deportes de la Universidad.

\section{Monografías sobre Enseñanza superior}

Cañellas, Celia; Torán, Rosa (1985). Els plans d'estudi de batxillerat a Espanya (1857-1903). En Actes de les VII jornades d'Història de l'Educació als Països Catalans «Escola $i$ Estat». Perpinyà, 2 al 5 de maig 1985 (99-125). Vic: Eumo.

Díaz de la Guardia Bueno, Emilio (1988). Evolución y desarrollo de la enseñanza media en España de 1875 a 1930. Un conflicto politico y pedagógico. Madrid: CIDE.

Frutos, Eugenio (1951). La enseñanza Media en España en la primera mitad del siglo XX. Bordón, Madrid, vol. III, núm. 17-18 (enero-febrero), 119-136.

Utande Igualada, Manuel (1964). Planes de estudio de la Enseñanza Media (1787-1963). Madrid: M. E. N., Dirección General de Enseñanza Media. Publicaciones de la «Revista de Enseñanza Media».

Viñao Frago, Antonio (1991). Del Bachillerato a la Enseñanza Secundaria (1938-1990). Revista Española de Pedagogía, Madrid, año L, núm. 192 (mayo-agosto), 321-339.

\section{Para citar este artículo}

Galera Pérez. A.D. (2019). Asignaturas de educación física en los planes de estudios de la Escuela española (1857-1970). Revista Fuentes, 21(1), 51-71 [Fecha de consulta: dd/mm/aa]. doi: http://dx.doi.org/10.12795/revistafuentes.2019.v21.i1.04 